\title{
Dependência espacial em levantamentos do estoque de carbono em áreas de pastagens de Brachiaria brizantha cv. Marandu
}

\author{
Sabino Pereira da SILVA NETO ${ }^{1}$, Antonio Clementino dos SANTOS ${ }^{2}$, Raimundo Laerton de LIMA LEITE ${ }^{1}$, \\ Valdinéia Patrícia DIM², Durval Nolasco das NEVES NETO², Rossini Sôffa DA CRUZ²
}

\section{RESUMO}

Foi conduzido um estudo utilizando análise de semivariogramas para quantificar a autocorrelaçáo espacial dos estoques de carbono (EC) no solo, biomassa da gramínea e das plantas daninhas em três parcelas experimentais de pastagens de Brachiaria brizantha cv. Marandu com níveis baixo, médio e alto de degradação, cultivadas em Neossolo Quartzarênico Órtico. As coletas das plantas e do solo foram realizadas em malha de amostragem regular com distâncias de 5 x $5 \mathrm{~m}$ em área de 900 $\mathrm{m}^{2}$. Os EC das pastagens foram submetidos às analises de estatística descritiva, ao teste não-paramétrico de Kruskal-Wallis ao nível de 5\% de significância, ao estudo geoestatístico e interpolação por krigagem ordinária. A variabilidade espacial do EC foi observada dentro e entre as pastagens de capim-Marandu com níveis baixo, médio e alto de degradaçáo. A pastagem de capim-Marandu com nível baixo de degradaçáo teve menor continuidade espacial, por apresentar menores alcances no EC, na biomassa da gramínea e na biomassa total (gramínea + plantas daninhas), no solo e no sistema solo x pastagem (solo + biomassa total). A grade de $5 \times 5 \mathrm{~m}$ foi adequada para caracterizar a variabilidade espacial de pastagens de capim-Marandu com níveis de degradação baixo e alto. Área de pastagem de capim-Marandu com grau médio de degradação apresenta coeficientes de variação altos entre os valores EC; o que comprometeu a modelagem espacial que também pode ter ocorrido devido ao baixo número de amostras realizadas $(\mathrm{n}=36)$. Assim, pontos de amostragem menores que $5 \mathrm{~m}$ podem melhorar a precisão dos ajustes dos semivariogramas.

PALAVRAS-CHAVE: $\mathrm{CO}_{2}$, degradação de pastagem, geoestatística, inventário do carbono, sequestro de carbono.

\section{Spatial dependence in surveys of carbon storage in grassland areas of Brachiaria brizantha, Marandu grass.}

\begin{abstract}
A study was carried using semivariogram analysis to quantify spatial autocorrelation of carbon stock (CS) in soil, grass and weed species biomass in pastures of Brachiaria brizantha, Marandu grass with low, medium and high degradation, and grown an entisol. The sampling of plants and soil were carried out in regular grid with distances of $5 \times 5 \mathrm{~m}$ in an area of $900 \mathrm{~m}^{2}$. Grassland CS was assessed through descriptive statistics, comparison of averages through the test Kruskal-Wallis at $5 \%$ level of significance, geostatistics and ordinary kriging analysis. The spatial variability of CS was observed within and between pastures with low, medium and high degradation. Pastures with low levels of degradation had less spatial continuity due to smaller ranges in CS in grass biomass and total biomass (grass + weed species), in soil carbon and soil versus grass (total biomass + soil). The grid of $5 \times 5 \mathrm{~m}$ was adequate to characterize the spatial variability of pasture with low and high levels of degradation. Areas of Marandu grass with average degree of degradation has high coefficients of variation (CV) between the CS values, which negative by affected the spatial modeling. High CV may also be due to the low number of samples taken $(\mathrm{n}=36)$. Sampling points in grid lower than $5 \mathrm{~m}$ can improve the accuracy of the adjustment of semivariograms.
\end{abstract}

KEYWORDS: $\mathrm{CO}_{2}$, degraded pasture, geostatistics, inventory of carbon, carbon sequestration.

1 Instituto Federal de Educação, Ciência e Tecnologia do Tocantins. Alameda Madri, 545, Jardim Sevilha, Gurupi - T0, CEP: 77410-470.

E-mail: sabinozootec@yahoo.com.br, laerton.leite@bol.com.br

2 Universidade Federal do Tocantins. Doutorando em Ciência Animal Tropical. Rod. BR 153, Km 112, Cx Postal 132.

E-mail: valpatdim@hotmail.com, durval.nolasco@gmail.com, rossinizoot@hotmail.com

2 Universidade Federal do Tocantins. Rod. BR 153, Km 112, Cx Postal 132. E-mail:clementino@uft.edu.br 


\section{INTRODUÇÃO}

As pastagens, base da produçáo animal no Brasil, constituem em um dos maiores e mais importantes agroecossistemas do país. O funcionamento deste ecossistema é caracterizado por fluxos de energia (radiação, calor) e de massa $\left(\mathrm{CO}_{2}, \mathrm{H}_{2} \mathrm{O}, \mathrm{N}\right.$, minerais) entre as plantas de uma população, o solo e a atmosfera, representados pelos diferentes processos fisiológicos de captação de energia e nutrientes (Silva et al. 2008). A falta de conhecimento destes processos leva à aplicação de manejo incorreto, caracterizado pela falta de adubação de manutenção, e excesso de animais, que resulta em superpastejo (Boddey et al. 2004).

Estimativas recentes têm sugerido que pelo menos a metade das áreas de pastagens em regiôes ecologicamente importantes, como a Amazônia e o Brasil Central, encontramse em degradação ou degradada (Dias-Filho 2006). Isso se dá, principalmente em áreas de pastejo, que são exploradas em sistemas extrativistas, rudimentares e pouco profissionais que negligenciam a fertilidade dos solos.

De acordo com Dias-Filho (2006) o processo de degradação é um fenômeno complexo que envolve causas e consequências primárias e secundárias que levam à gradativa reduçấo da capacidade de suporte, o que afeta diretamente a produçấo e o desempenho animal e culmina com a degradaçáo do solo e dos recursos naturais. Nesse sentido, a degradaçáo pode estar relacionada à deterioração das propriedades físicoquímicas do solo e com a produtividade da pastagem.

O processo de degradação também altera significativamente os estoques de carbono (EC) do solo (Smith et al. 2008). De acordo com Conant et al. (2001) melhorias no manejo da pastagem e conservação do solo, destinadas a aumentar a produção da gramínea, geralmente elevam o EC. Nesses sistemas ecológicos terrestres, onde o carbono é retido em forma de biomassa viva, matéria orgânica em decomposição e no solo, tem um papel importante no ciclo global do carbono (IPCC 2000).

O EC do solo representa o balanço dinâmico entre a adiçáo de material vegetal morto e a perda pela decomposiçáo ou mineralização (Scholes et al. 1997). Este estoque, bem como outros atributos do solo, determina o impacto das atividades agrícolas ao meio ambiente, que podem variar com tempo e também no espaço, razão pelo qual o conhecimento da sua variabilidade espacial é importante, sobretudo, para o ajuste fino das práticas de manejo e avaliação dos efeitos da agricultura sobre a qualidade ambiental (Cambardella et al. 1994).

A avaliação das mudanças nos EC em diferentes compartimentos da interface solo x pastagem é importante, pois quantifica as emissóes ou sequestros de carbono em dado momento, gerando assim inventários do armazenamento de carbono em diferentes depósitos e também mede o impacto na remoçáo do dióxido de carbono $\left(\mathrm{CO}_{2}\right)$ presente na atmosfera, por meio da sua fixaçáo na biomassa e no solo em sistemas de pastejo. Diante disso, o objetivo desse estudo foi levantar informaçôes sobre a variabilidade espacial do EC em área cultivadas com capim-Marandu com diferentes graus de degradação, bem como conhecer a escala ou a extensão que essa ocorre nessas áreas.

\section{MATERIAL E MÉTODOS}

A área de estudo está situada na fazenda da Escola de Medicina Veterinária e Zootecnia da Universidade Federal do Tocantins, Campus de Araguaína. De acordo com a classificação de Köppen a regiâo apresenta clima tipo Aw (quente úmido) com estação seca de abril a outubro. As precipitaçóes pluviométricas apresentam médias anuais de $1.800 \mathrm{~mm}$ e temperatura média de $28^{\circ} \mathrm{C}$. O solo do local foi classificado como Neossolo Quartzarênico Órtico típico, de acordo com Embrapa (2006).

A área experimental foi composta de vinte piquetes utilizados em lotação contínua sobre pastagem de Brachiaria brizantha cv. Marandu estabelecida no ano de 2006. Dentre esses piquetes foram selecionadas áreas com níveis de degradação baixo, médio e alto, conforme a classificação de Spain e Gualdrón (1988), por meio de critério visual. Os três piquetes selecionados eram pastejados por seis novilhos zebuínos com peso médio de $300 \mathrm{~kg}$ que permaneciam nestas áreas por 35 dias.

Em cada piquete foi demarcada uma área de $900 \mathrm{~m}^{2}$ $(30 \times 30 \mathrm{~m})$ que continham 36 pontos de amostragem georreferenciados dispostos em malha de 5 x $5 \mathrm{~m}$. Em cada ponto georreferenciado realizou-se a coleta de solo na profundidade de $0-20 \mathrm{~cm}$, com sonda de amostragem e da forragem com quadro de amostragem de $0,5 \mathrm{~m}^{2}(0,5 \times 1 \mathrm{~m})$.

Para comparar os níveis baixo, médio e alto de degradação da pastagem de capim-Marandu, fez-se a discriminação destas pelo teste náo-paramétrico de Kruskal-Wallis ao nível de 5\% de significância uma vez que os dados não apresentaram normalidade. A comparação foi realizada entre as respostas produtivos da gramínea e a infestação por plantas daninhas em cada nível de degradação das pastagens de capim-Marandu.

Após as coletas todas as amostras de solo, foram secas ao ar e peneiradas em peneira de malha de 2,0 mm e então obtidas amostras de terra fina seca ao ar (TFSA), para posteriores análises física e química. Nessas amostras de solo, foi determinada a densidade do solo e o carbono orgânico total (COT), conforme Embrapa (1997).

O EC do solo em cada um dos locais amostrados foi estimado com a expressão: $\mathrm{EC}=(\mathrm{COT} \times \mathrm{x}$ x $\mathrm{e}) / 10$, em que EC é o estoque de carbono do solo em $\mathrm{Mg} \mathrm{ha}^{-1}$; COT indica o teor de carbono orgânico total $\mathrm{em} \mathrm{kg}^{-1}$; Ds é a densidade do solo em $\mathrm{kg} \mathrm{dm}^{-3}$ e "e" é a profundidade de coleta do solo $\mathrm{em} \mathrm{cm}$. 
A forragem foi colhida rente ao solo e colocada em sacos identificados, levados para pesagem e separaçáo manual dos componentes morfológicos (folhas verdes, colmo + bainha foliar e material morto) e botânico (plantas daninhas). Em seguida, esses componentes foram acondicionados em sacos de papel identificados, e levados à estufa de circulação de ar forçada para secagem a $55^{\circ} \mathrm{C}$ por 72 horas. Após secagem as amostras foram pesadas e seus pesos $\left(\mathrm{kg} 0,5 \mathrm{~m}^{-2}\right)$ foram então convertidos para produçôes de massa seca total (MST) de plantas daninhas e da gramínea em $\mathrm{Mg} \mathrm{ha}^{-1}$ com a expressão:

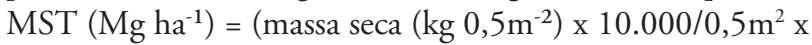
1.000). A estimativa do EC na biomassa da gramínea e das plantas daninhas foi obtida pela multiplicaçáo das respectivas biomassas obtidas em $\mathrm{Mg} \mathrm{ha}^{-1}$ pelo fator 0,5 conforme recomendaçóes do IPCC (2006).

Os dados do EC do solo, da biomassa da gramínea e das plantas daninhas foram avaliados por meio da estatística descritiva calculando-se a média, mediana, variância, assimetria, curtose, o coeficiente de variaçáo e o tipo de distribuição. Utilizou-se o teste de Kolmogorov-Smirnov a 5\% de significância para verificar a hipótese de normalidade. Para fins de comparação, foram adotados os limites do coeficiente de variação (CV) propostos por Warrick e Nielsen (1980), para a classificação da variabilidade dos atributos avaliados em: baixa $(C V<12 \%)$, média $(12<\mathrm{CV}<60 \%)$ e alta $(\mathrm{CV}>60 \%)$.

$\mathrm{O}$ padráo de dependência espacial foi caracterizado por meio de análise geoestatística, calculando-se a semivariância com a equação proposta por Matheron (1963):

$\gamma(\mathrm{h})=\frac{1}{2 \mathrm{~N}(\mathrm{~h})} \sum_{\mathrm{i}=1}^{\mathrm{N}(\mathrm{h})}\left[\mathrm{Z}\left(\mathrm{x}_{\mathrm{i}}\right)-\mathrm{Z}\left(\mathrm{x}_{\mathrm{i}}+\mathrm{h}\right)\right]^{2}$ sendo $\mathrm{N}(\mathrm{h})$ o número de pares de valores experimentais medidos em $\left[\mathrm{Z}\left(\mathrm{x}_{\mathrm{i}}\right), \mathrm{Z}\left(\mathrm{x}_{\mathrm{i}}+\right.\right.$ h)], separados pelo vetor $h$. No presente estudo, os valores de $\mathrm{Z}$ foram os $\mathrm{EC}$ nos diferentes compartimentos, enquanto os valores de $x_{i}$ e $x_{i}+h$ foram definidos de acordo com a localização geográfica das amostras realizadas no campo. Os valores da semivariância experimental foram determinados pelo programa $\mathrm{GS}^{+}$(Robertson 1998).

Inicialmente foi realizado o ajuste visual do modelo selecionado à nuvem de pontos do semivariograma experimental. Nesse estudo foram testados os modelos de semivariogramas: (a) esférico, $\gamma(\mathrm{h})=\mathrm{C}_{0}+\mathrm{C}_{1}[1,5(\mathrm{~h} / \mathrm{A})-0,5$ $\left.(\mathrm{h} / \mathrm{A})^{3}\right]$ para $(0<\mathrm{h} \leq \mathrm{A})$ e $\gamma(\mathrm{h})=\mathrm{C}_{0}+\mathrm{C}_{1}$ para $\mathrm{h}>\mathrm{A}$; (b) exponencial, $\gamma(\mathrm{h})=\mathrm{C}_{0}+\mathrm{C}_{1}[1-\exp (-\mathrm{h} / \mathrm{A})]$; e (c) gaussiano, $\gamma(\mathrm{h})=\mathrm{C}_{0}+\mathrm{C}_{1}\left[1-\exp \left(-\mathrm{h}^{2} / \mathrm{A}^{2}\right)\right]$ em que "d" é a distância máxima na qual o semivariograma é definido e "A" o alcance. $\mathrm{O}$ ajuste dos semivariogramas possibilitou definir os valores do efeito pepita $\left(\mathrm{C}_{0}\right)$, do alcance $(\mathrm{A})$ e do patamar $\left(\mathrm{C}+\mathrm{C}_{0}\right)$.

Finalmente a seleção do modelo ajustado dos semivariogramas, foi realizada com base na minimização da soma dos quadrados dos resíduos (SQR) e no maior coeficiente de determinação múltipla $\left(\mathrm{R}^{2}\right)$. Além disso, avaliou-se o desempenho de cada modelo por meio do critério de Akaike
(AIC) com a utilizaçáo do programa Vesper 1.6 (Minasny et al. 2006). Esse critério é dado pela seguinte expressão: AIC = $-2 \log \mathrm{L}+2 \mathrm{~K}$ em que $\mathrm{L}$ é a verossimilhança maximizada pelo modelo candidato e K é o número de parâmetros do modelo considerado.

Para análise do grau de dependência espacial (GDE) foi utilizada a proporção dada pela equação: $\mathrm{GDE}=\left[\frac{\mathrm{C}}{\mathrm{C}+\mathrm{C}_{0}}\right] 100$ que permite classificar o GDE em dependência espacial fraca (GDE $\leq 25 \%)$, dependência espacial moderada $(25 \%<$ $\mathrm{GDE} \leq 75 \%)$ e dependência espacial forte (GDE > 75\%) (Cambardella et al. 1994).

A interpolação dos valores foi realizada pelo método geoestatístico de krigagem ordinária, de modo a definir o padrão espacial EC, o que permitiu a elaboração dos mapas de isolinhas com o auxílio da equação: $Z^{*}\left(x_{0}\right)=\sum_{i=1}^{N} \lambda_{i} Z\left(x_{i}\right) e m$ que $Z^{*}\left(x_{0}\right)$ é o $E C ; \lambda_{i}$ é o peso da i-ésima localidade vizinha; $\mathrm{Z}\left(\mathrm{x}_{\mathrm{i}}\right)$ é o valor da variável para a i-ésima localidade; e $\mathrm{N}$ é o número de localidades vizinhas empregadas para interpolaçáo do ponto (Vieira 2000). Os mapas de variabilidade espacial foram construídos usando o programa Surfer 8.0 (Golden Software 2002).

\section{RESULTADOS E DISCUSSÃO}

A produção de massa seca dos componentes morfológicos da gramínea e das plantas daninhas nas áreas de pastagens de Brachiaria brizantha cv. Marandu, classificadas inicialmente por estimativa visual foram influenciadas pelos níveis de degradação (Tabela 1). Nas pastagens com níveis baixos e médios de degradaçáo a produção de massa seca total (MST) foi maior que no nível alto. Já a produção de massa seca de plantas daninhas (MSPD) nas áreas com nível baixo e médio foi menor que à pastagem com alto nível de degradação.

A produção de massa seca de folhas verdes (MSFV) das pastagens de capim-Marandu, reduziu com o aumento do nível de degradação. Assim, o nível baixo teve maior produção de MSFV em relação ao nível médio o qual foi maior que o nível alto.

Tabela 1 - Proporções dos componentes morfológicos da gramínea e produção de plantas daninhas em três parcelas experimentais de pastagens de Brachiaria brizantha cv. Marandu com diferentes graus de degradação.

\begin{tabular}{|c|c|c|c|c|}
\hline \multirow{2}{*}{ Variável } & \multicolumn{3}{|c|}{ Grau de degradação } & \multirow{2}{*}{$\mathrm{CV}^{1}$} \\
\hline & Baixo & Médio & Alto & \\
\hline & \multicolumn{3}{|c|}{ 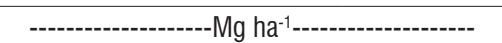 } & -------\%------- \\
\hline $\mathrm{MST}^{2}$ & $8,18(0,57) \mathrm{a}$ & $7,87(0,53) \mathrm{a}$ & $3,00(0,41) b$ & 44,23 \\
\hline MSFV$^{3}$ & $3,09(0,24) \mathrm{a}$ & $2,17(0,24) b$ & $0,92(0,13) \mathrm{c}$ & 48,76 \\
\hline $\mathrm{MSC}^{4}$ & $2,92(0,27) \mathrm{a}$ & $2,67(0,21) \mathrm{a}$ & $1,02(0,16) b$ & 54,55 \\
\hline MSMM $^{5}$ & $2,17(0,18) \mathrm{a}$ & $3,03(0,27) \mathrm{a}$ & $1,06(0,16) b$ & 56.17 \\
\hline MSPD $^{6}$ & $0,06(0,03) b$ & $0,04(0,02) b$ & $2,16(0,55) \mathrm{a}$ & 209,79 \\
\hline
\end{tabular}

Médias seguidas de mesma letra nas linhas não diferem entre si (Kruskal-Wallis, 5\%). Valores entre parênteses referem-se ao erro padrão da média.

(1)CV: coeficiente de variação;; (2)MST: massa seca total; ; ${ }^{(3)}$ MSFV: massa seca de folhas verdes; (4)MSC: massa seca de colmo; (5)MSMM: massa seca de material morto; ${ }^{(6)}$ MSPD: massa seca de plantas daninhas. 
A maior produção de massa seca de colmo (MSC) foi encontrada nas pastagens com níveis baixos e médios de degradação as quais não se diferiram. Nesse sentido, a menor produção de MSC foi observada na área com nível alto de degradaçáo. Situaçáo perfeitamente compreensível, pois o aumento na produçáo de MSFV leva ao maior sombreamento na base da touceira o que desencadeia o processo de alongamento de colmo (Gomide et al. 2003).

A pastagem de capim-Marandu nos níveis baixo e médio de degradação apresentou maior produção de massa seca de material morto (MSMM) que o nível alto de degradação. Isso indica que as possíveis condiçôes de manejo empregadas a esse níveis de degradação tal como subpastejo ou atrasos na ocupação do piquete pelos bovinos, favorecem o crescimento da gramínea, mas não manteve de forma estável o desenvolvimento da planta devido à ausência da adubação de manutenção, o que ativa o processo de translocação de nutrientes das folhas velhas causando assim a morte destas (Gomide et al. 2002). Já em condições de alta degradação, onde as praticas de manejo são totalmente precárias, o crescimento da gramínea é reduzido tendo assim baixa renovaçáo de tecido vegetal e menor alocaçáo de nutrientes de outras folhas (Gomide et al. 2003).

Os resultados do teste de normalidade de KolmogorovSmirnov indicam que o EC na biomassa da gramínea e na total (Gramínea + Plantas daninhas) tem distribuição normal nos níveis baixo e alto de degradaçáo (Tabela 2). Já para o EC das plantas daninhas nos níveis baixo, médio e alto, a normalidade náo foi observada. No solo e no sistema solo $\mathrm{x}$ planta (Solo + Biomassa total) apenas no nível baixo o EC não foi normalmente distribuído.

Os valores do coeficiente de variaçáo $(\mathrm{CV})$ indicam que o conjunto de dados apresenta alta heterogeneidade, pois os EC na biomassa das plantas daninhas nos diferentes níveis de degradação e na biomassa da gramínea no nível alto possuem alta variabilidade $(\mathrm{CV}>60 \%)$ conforme a classificação Warrick e Nielsen (1980). Essa resposta já era esperada, pois em certos momentos foram identificados locais que não apresentavam plantas daninhas, apenas a gramínea e outros com elevada concentraçấo de invasoras. De acordo com Shaffrath et al. (2007) a alta variação nos dados é típica de estudos com plantas daninhas, pois essas se distribuem na área em manchas ou reboleiras. Mesma situação foi observada por Chiba et al. (2010) estudando a variabilidade espacial de invasoras em sistema de plantio direto. Nas demais variáveis e níveis de degradaçấo da pastagem o CV mostrou que os dados têm média variabilidade.

Esses resultados do $\mathrm{CV}$ indicam que a utilização de valores médios não caracteriza adequadamente a variabilidade do EC em áreas de pastagem. Acarretando assim erros na distinção da área devido ao uso desses valores médios com alta variabilidade. Essas condiçôes podem levar à sub ou superestimativas no EC.

Tabela 2 - Estatística descritiva dos componentes do estoque de carbono em três parcelas experimentais de pastagens de Brachiaria brizantha cv. Marandu com diferentes graus de degradação.

\begin{tabular}{|c|c|c|c|c|c|c|c|}
\hline \multirow{2}{*}{ Grau de degradação } & \multirow{2}{*}{ Média } & \multirow{2}{*}{ Mediana } & \multirow[t]{2}{*}{ Variância } & \multicolumn{3}{|c|}{ Coeficiente } & \multirow{2}{*}{$\mathrm{KS}^{1}$ (p-valor) } \\
\hline & & & & Variação & Assimetria & Curtose & \\
\hline \multicolumn{8}{|c|}{ Gramínea } \\
\hline Baixo & $4,09(0,28) \mathrm{a}$ & 3,89 & 2,48 & 38,53 & 0,15 & 1,25 & $0,18^{*}$ \\
\hline Médio & $3,93(0,26) \mathrm{a}$ & 3,63 & 2,12 & 37,08 & 1,01 & 0,78 & $0,007^{\star *}$ \\
\hline Alto & $1,50(0,20) b$ & 1,33 & 1,30 & 75,99 & 0,36 & $-0,36$ & $0,52^{\star}$ \\
\hline \multicolumn{8}{|c|}{ Plantas daninhas } \\
\hline Baixo & $0,03(0,01) b$ & 0,00 & 0,008 & 293,09 & 3,21 & 10,03 & $5,82 \times 10^{-19 * *}$ \\
\hline Médio & $0,02(0,01) b$ & 0,00 & 0,005 & 333,35 & 3,77 & 13,83 & $5,33 \times 10^{-15 * \star}$ \\
\hline Alto & $1,08(0,25) \mathrm{a}$ & 0,66 & 1,88 & 126,90 & 1,64 & 2,93 & $1,05 \times 10^{-3 \star \star}$ \\
\hline \multicolumn{8}{|c|}{ Biomassa Total (Gramínea + Plantas daninhas) } \\
\hline Baixo & $4,12(0,28) \mathrm{a}$ & 3,91 & 2,44 & 37,90 & 0,11 & 1,37 & $0,48^{*}$ \\
\hline Médio & $3,95(0,27) \mathrm{a}$ & 3,64 & 2,19 & 37,44 & 0,99 & 0,63 & $0,05^{\star}$ \\
\hline Alto & $2,58(0,22) b$ & 2,4 & 1,52 & 47,70 & 0,72 & 0,07 & $0,28^{*}$ \\
\hline \multicolumn{8}{|c|}{ Solo } \\
\hline Baixo & $34,62(1,93)$ a & 33,93 & 111,88 & 30,54 & 0,97 & 0,71 & $1,04 \times 10^{-4 * *}$ \\
\hline Médio & $28,54(1,79) b$ & 28,93 & 96,94 & 34,49 & 0,94 & 3,01 & $0,28^{\star}$ \\
\hline Alto & $32,57(1,24) a b$ & 32,11 & 46,27 & 20,88 & 0,70 & 1,85 & $0,52^{*}$ \\
\hline \multicolumn{8}{|c|}{ Sistema solo x planta (Solo + Biomassa total) } \\
\hline Baixo & $38,75(1,96) \mathrm{a}$ & 37,57 & 115,44 & 27,72 & 1,00 & 0,47 & $2,73 \times 10^{-3 \star \star}$ \\
\hline Médio & $32,49(1,86) \mathrm{a}$ & 32,98 & 103,83 & 31,35 & 0,83 & 2,54 & 0,30 * \\
\hline Alto & $35,15(1,26) \mathrm{a}$ & 35,53 & 47,69 & 19,64 & 0,23 & 1,13 & $0,70^{*}$ \\
\hline
\end{tabular}

Médias seguidas de mesma letra na coluna para cada componente não diferem entre si (Kruskal-Wallis, 5\%).

Valores entre parênteses referem-se ao erro padrão da média.

(1)KS: teste de normalidade Kolmogorov-Smirnov, $\left({ }^{*}\right)$ : significativo a $5 \%,\left({ }^{* *}\right)$ : não-significativo a $5 \%$. 
O EC foi influenciado pelos níveis de degradaçáo da pastagem de capim-Marandu. Os maiores EC foram encontrados na biomassa da gramínea e na biomassa total (Gramínea + Plantas daninhas) nas pastagens com grau baixo e médio de degradação, e os menores no nível alto. Já na biomassa das plantas daninhas como era esperado, situação contraria ocorreu com menores estoques nos níveis baixo e médio e maiores no nível alto de degradaçáo. No solo os maiores EC foram encontrados na pastagem com nível baixo de degradação e os menores no nível médio. No sistema solo $x$ planta (Solo + Biomassa total) não houve diferença entre as áreas de pastagem.

Considerando-se esses resultados, o processo de degradação da pastagem de capim-Marandu resulta na diminuiçáo da produção de MSFV e no aumento da infestaçáo por plantas daninhas. Nesse sentido, a maior produçáo de MS dos níveis baixo e médio de degradaçáo culminou em maior EC na biomassa da gramínea em relação ao nível alto de degradação. Apesar disso, o nível alto de degradaçáo manteve seu EC no solo menor igual ao baixo nível e maior igual ao nível médio. Situaçáo justificável, pois o aumento na proporção de plantas daninhas e consequente diminuição do capim necessariamente não deterioram as propriedades físico-químicas do solo que em certos casos podem até melhorar devido ao aumento da cobertura arbóreo-arbustiva (Dias-Filho 2006).

O EC no solo é determinado em grande parte pela entrada de carbono a partir dos resíduos vegetais (material senescente) não consumidos pelos animais (Schlesinger 2000, Thuille $e t$ al. 2000) ou pela incorporação proveniente da decomposição do sistema radicular da pastagem (Faria et al. 2010).

Müller et al. (2004) concluíram que a degradação de pastagens Brachiaria na região amazônica não está ligada diretamente com a concentração de carbono orgânico do solo e sim, na redução da capacidade produtiva e de suporte animal. Mesma situação foi verificada por Oliveira et al. (2004) em pastagem degradadas na regiáo de Cerrado. Entretanto, Conant et al. (2001) sugerem que melhorias no manejo da pastagem e conservaçâo do solo destinadas a aumentar a produção da gramínea, geralmente aumenta o carbono orgânico do solo, situaçáo que foi observada na pastagem com baixa degradação.

Diante disso, observa-se que pastagens bem manejadas com baixo nível de degradação têm potencial de sequestrar maior quantidade de carbono e, também, de manter sua produtividade com características desejáveis para a produção animal, tal como alta proporção de MSFV e baixa de MSPD em relaçáo a MST conforme foi relatado por Conant $e t$ al. (2001).

As alteraçóes do EC provocadas pela degradação das pastagens e pela alta variabilidade dos dados de acordo com os CVs encontrados (Tabela 2) sugerem que as informaçóes a respeito da variabilidade espacial as variáveis deve ser incorporadas, por meio de estudos de autocorrelaçáo espacial (Kravchenko et al. 2006b), que ajudaria a reduzir o erro padrão das estimativas médias (Cerri et al. 2004).

O grau de dependência espacial (GDE) apresentou, em 12 das 13 situaçôes com modelos estabelecidos, classe moderada de GDE que variou de 35 a 60\% nos três níveis de degradaçáo da pastagem (Tabela 3). No entanto, o EC na biomassa das plantas daninhas e total teve GDE forte na área com alta degradação da pastagem. Conforme sugerido por Cambardella et al. (1994) e Castrignanò et al. (2000), a forte dependência espacial das características do solo é atribuída aos fatores intrínsecos tais como material de origem, clima, relevo, processos físicos, químicos e atividade biológica (componentes de formaçáo do solo) e a dependência espacial moderada aos fatores extrínsecos como o manejo exercido pelas práticas agrícolas.

Os maiores GDE indicam que se tem melhor estrutura espacial e que maior precisão pode ser obtida no mapeamento das propriedades estudadas usando técnicas de geoestatística como a krigagem (Kravchenko et al. 2006b). A análise variográfica indica que todos os compartimentos do EC apresentam dependência espacial nos três níveis de degradação da pastagem de capim-Marandu, com modelos matemáticos dos semivariogramas omnidirecionais ajustados aos modelos esférico e exponencial (Figura 1).
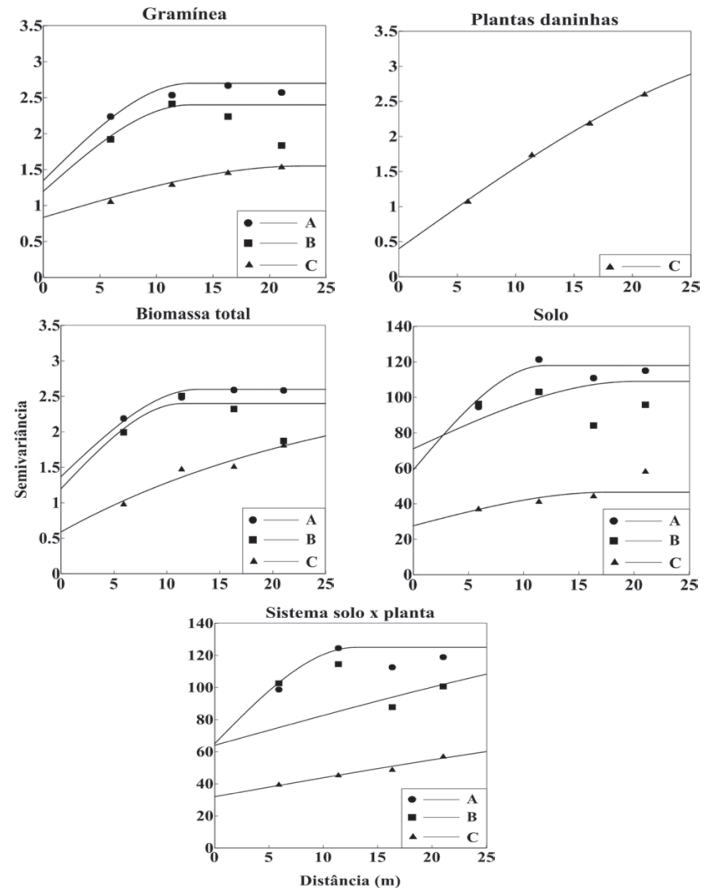

Figura 1 - Semivariogramas ajustados aos valores de estoque de carbono na biomassa da gramínea, na biomassa da planta daninha no nível alto de degradação, na biomassa total, no sol e no sistema solo x planta em três parcelas experimentais de pastagens de capim-Marandu com nível baixo (A), médio (B) e alto (C) de degradação, respectivamente. 
Tabela 3 - Modelos e parâmetros estimados dos semivariogramas ajustados aos valores do estoque de carbono em três parcelas experimentais de pastagens de Brachiaria brizantha cv. Marandu em diferentes graus de degradação.

\begin{tabular}{|c|c|c|c|c|c|c|c|c|c|}
\hline \multirow{3}{*}{$\begin{array}{l}\text { Grau de } \\
\text { degradação }\end{array}$} & \multicolumn{9}{|c|}{ Parâmetro } \\
\hline & \multirow{2}{*}{ Modelo } & $\mathrm{C}_{0}{ }^{1}$ & $\mathrm{C}_{0}+\mathrm{C}^{2}$ & $A^{3}$ & $\mathrm{GDE}^{4}$ & \multirow{2}{*}{ Classe } & \multirow{2}{*}{$\mathrm{R}^{2^{*}}$} & \multirow{2}{*}{$\mathrm{SQR}^{5}$} & \multirow{2}{*}{$\mathrm{AlC}^{6}$} \\
\hline & & \multicolumn{2}{|c|}{---Mg C ha'---- } & ----m---- & ----\%---- & & & & \\
\hline & \multicolumn{9}{|c|}{ Gramínea } \\
\hline Baixo & Esférico & 1,35 & 2,70 & 13,00 & 50 & Moderada & 0,93 & 0,037 & $-5,37$ \\
\hline Médio & Esférico & 1,20 & 2,40 & 13,00 & 50 & Moderada & 0,16 & 0,352 & 1,09 \\
\hline \multirow[t]{2}{*}{ Alto } & Esférico & 0,836 & 1,55 & 22,94 & 51 & Moderada & 1,00 & $3,06 \mathrm{E}^{-5}$ & $-25,13$ \\
\hline & \multicolumn{9}{|c|}{ Plantas daninhas } \\
\hline Baixo & EPP $\ddagger$ & - & - & - & - & - & - & - & $\cdot$ \\
\hline Médio & EPP $\ddagger$ & - & - & - & - & - & - & - & - \\
\hline \multirow[t]{2}{*}{ Alto } & Esférico & 0,401 & 3,25 & 36,07 & 88 & Forte & 0,99 & $1,83 \mathrm{E}^{-3}$ & $-26,96$ \\
\hline & \multicolumn{9}{|c|}{ Biomassa total (Gramínea + Plantas daninhas) } \\
\hline Baixo & Esférico & 1,37 & 2,60 & 13,00 & 47 & Moderada & 0,96 & $9,01 \mathrm{E}^{-3}$ & $-7,16$ \\
\hline Médio & Esférico & 1,20 & 2,40 & 11,50 & 50 & Moderada & 0,16 & 0,289 & $-0,25$ \\
\hline \multirow[t]{2}{*}{ Alto } & Exp† & 0,59 & 2,83 & 27,03 & 79 & Forte & 0,92 & 0,028 & $-17,73$ \\
\hline & \multicolumn{9}{|c|}{ Solo } \\
\hline Baixo & Esférico & 59,00 & 118,00 & 12,00 & 50 & Moderada & 0,85 & 92,1 & 38,29 \\
\hline Médio & Esférico & 71,00 & 109,00 & 20,00 & 35 & Moderada & 0,14 & 799 & 45,77 \\
\hline \multirow[t]{2}{*}{ Alto } & Esférico & 27,61 & 46,50 & 17,50 & 41 & Moderada & 0,54 & 149 & 36.90 \\
\hline & \multicolumn{9}{|c|}{ Sistema solo x planta (Solo + Biomassa total) } \\
\hline Baixo & Esférico & 65,00 & 125,00 & 13,00 & 48 & Moderada & 0,77 & 214 & 41,29 \\
\hline Médio & Esférico & 64,00 & 140,40 & 61,00 & 54 & Moderada & 0,15 & 1659 & 52,50 \\
\hline Alto & Esférico & 31,60 & 79,85 & 61,00 & 60 & Moderada & 0,96 & 6,17 & 23,74 \\
\hline
\end{tabular}

(1)C0: efeito pepita; (2)CO+C: patamar; (3)A: alcance; (4)GDE: grau de dependênciaespacial; (5)SQR: Soma do quadrado dos resíduos, (6)AIC: critério de Akaike, $\left({ }^{*}\right) \mathrm{R}^{2}$ : coeficiente de determinação, $¥$ EPP: efeito pepita pura, $¥$ Exp: exponencial.

Os semivariogramas do EC na biomassa da gramínea nos três níveis de degradação se ajustaram ao modelo esférico com melhores ajustes para o nível baixo e alto. Os alcances foram de 13,00 m para os níveis baixos e médios e de 22,94 $\mathrm{m}$ para pastagens com degradação alta. A menor continuidade espacial no nível baixo e médio pode ser reflexo direto da produção de biomassa da gramínea, pois em condiçôes de boa oferta de forragem os animais selecionam e escolhem as melhores estaçóes alimentares gerando assim diferentes locais de rebrota. Já em situação de baixa oferta de forragem (nível alto de degradaçáo) inexistem estaçôes rejeitadas durante o pastejo (Carvalho et al. 2009). Desse modo, a seletividade é praticamente igual a zero, o que mantém a rebrota igual por toda a área, aumentando assim a continuidade espacial.

A formaçáo de manchas de plantas com porte diferente das demais irá ocorrer em função da existência de locais com maior fertilidade e atividade biológica do solo (Salton e Carvalho 2007). Devido à deposição de dejetos dos animais e/ou maior acúmulo de material senescente, do pastejo desuniforme pela seleção e/ou rejeiçẫo de plantas pelos animais e das alteraçôes em atributos físicos do solo devido ao pisoteio dos animais.

$\mathrm{Na}$ biomassa das plantas daninhas o semivariograma do EC se ajustou ao modelo esférico no nível alto de degradação nos demais níveis ocorreu efeito pepita puro. Esse resultado está próximo aos encontrados por Chiba et al. (2010) que demonstraram que para densidade de plantas daninhas temse alcances variando de 28,5 a $77 \mathrm{~m}$ e os semivariogramas se ajustando aos modelos esférico e exponencial numa malha de amostragem de $10 \times 10 \mathrm{~m}$. Nesse compartimento o alcance do EC está provavelmente subestimado devido às limitaçóes do tamanho da parcela $(30 \times 30 \mathrm{~m})$. Como tal, é provável que a dependência espacial continue em escala maior do que a captada pelo presente experimento, o que pode permitir intervalos entre amostras ainda maiores.

$\mathrm{O}$ alcance de um atributo garante que todos os pontos dentro de um círculo com este raio são táo similares que podem ser usados para estimar valores para qualquer ponto entre eles (Machado et al. 2007). 
Os ajustes dos semivariogramas dos EC da biomassa total (Gramínea + Plantas daninhas) se adequaram ao modelo esférico nas áreas com baixa e média degradação. Já na pastagem com alta degradação o modelo que se ajustou foi o exponencial. Quanto ao alcance o maior $(27,03 \mathrm{~m})$ foi encontrado na área com alto nível de degradação e os menores no nível baixo $(13,00 \mathrm{~m})$ e médio (11,50 m), respectivamente.

Nos três níveis de degradação da pastagem os semivariogramas do EC do solo se ajustaram ao modelo esférico. $\mathrm{O}$ menor alcance foi no nível baixo $(12,00 \mathrm{~m})$ seguido pelo alto $(17,50 \mathrm{~m})$ e o maior $(20,00 \mathrm{~m})$ no nível médio de degradaçấo da pastagem. Worsham et al. (2010) observaram alcance do conteúdo de $\mathrm{C}$ do solo variando de 31,5 a 98,8 $\mathrm{m}$ em áreas de pastagens. Já Kravchenko et al. (2006a) encontraram alcances que iam de 15 a $64 \mathrm{~m}$.

Finalmente, o EC do sistema solo x planta (Solo + Biomassa total) os semivariogramas se adequaram ao modelo esférico nos níveis baixo, médio e alto de degradação da pastagem. A área com nível baixo de degradação teve o menor alcance $(13,00 \mathrm{~m})$ em relação aos locais com nível médio e alto que tiveram alcance de $61,00 \mathrm{~m}$. Assim como no EC na biomassa de plantas daninhas os alcances no nível médio e alto podem está subestimados devido ao tamanho das parcelas. Além disso, a quantidade de amostra $(\mathrm{n}=36)$ pode ter sido insuficiente para a modelagem espacial do EC pois conforme Webster e Oliver (1992) amostra com número inferior a 50 comprometem o ajuste dos semivariogramas.

De acordo com os resultados a estratificação da pastagem em níveis de degradaçáo permitiu caracterizar e estimar o EC atual nos compartimentos da interface solo x planta. Assim, a partir dos modelos obtidos, nos semivariogramas ajustados para cada pastagem estudada, estimaram-se os valores do EC para os locais nẫo amostrados por intermédio da interpolaçấo de krigagem ordinária. Finalmente, com os valores estimados foi possível construir mapas de isolinhas (Figuras 2, 3, 4, 5 e 6) que expressam a variabilidade do EC em função do nível de degradação da pastagem. De acordo com Feng et al. (2004) a geoestatística permite caracterizar e quantificar a variabilidade espacial, desenvolver uma interpolaçáo racional e estimar a variância dos valores interpolados. Os mapas confeccionados permitiram visualizar arranjos de distribuiçấo espacial, do $\mathrm{EC}$, bem distintos entre as pastagens o que proporcionou à identificaçáo de zonas de concentração de carbono em função da degradaçáo da pastagem. Além disso, permitiu observar o impacto da degradaçấo das pastagens no sequestro de carbono.

A identificação destas zonas de manejo surge como ferramenta auxiliar que traz economia de insumos e preservação da qualidade ambiental pela aplicação de volumes de herbicidas e de fertilizantes em função da real situação da pastagem. Além disso, conforme sugerido por Laca (2009) pode auxiliar a compreender e monitorar padróes comportamentais dos animais e interaçóes com a vegetaçáo em ambiente heterogêneo. Além de criar práticas de manejo de pastagem que minimizem a heterogeneidade dos recursos forrageiros, otimizando a eficiência de uso destes. Segundo Conant et al. (2001) e Igram et al. (2008), essas melhorias no manejo da pastagem aumenta o carbono orgânico do solo e diminuem as perdas para a atmosfera.

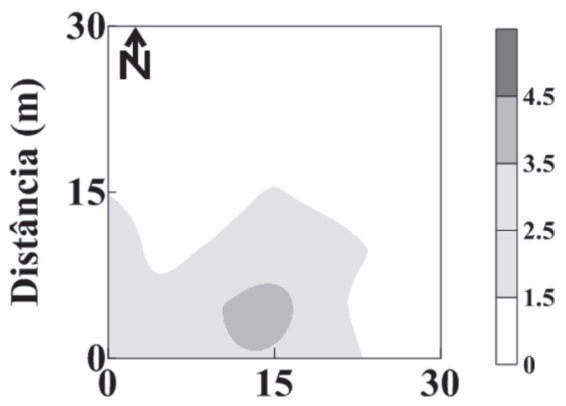

\section{Distância (m)}

Figura 3 - Mapa de isolinhas da distribuição espacial do estoque de carbono $\left(\mathrm{Mg} \mathrm{ha}^{-1}\right)$ da biomassa das plantas daninhas em pastagem de capim-Marandu com nível alto de degradação.
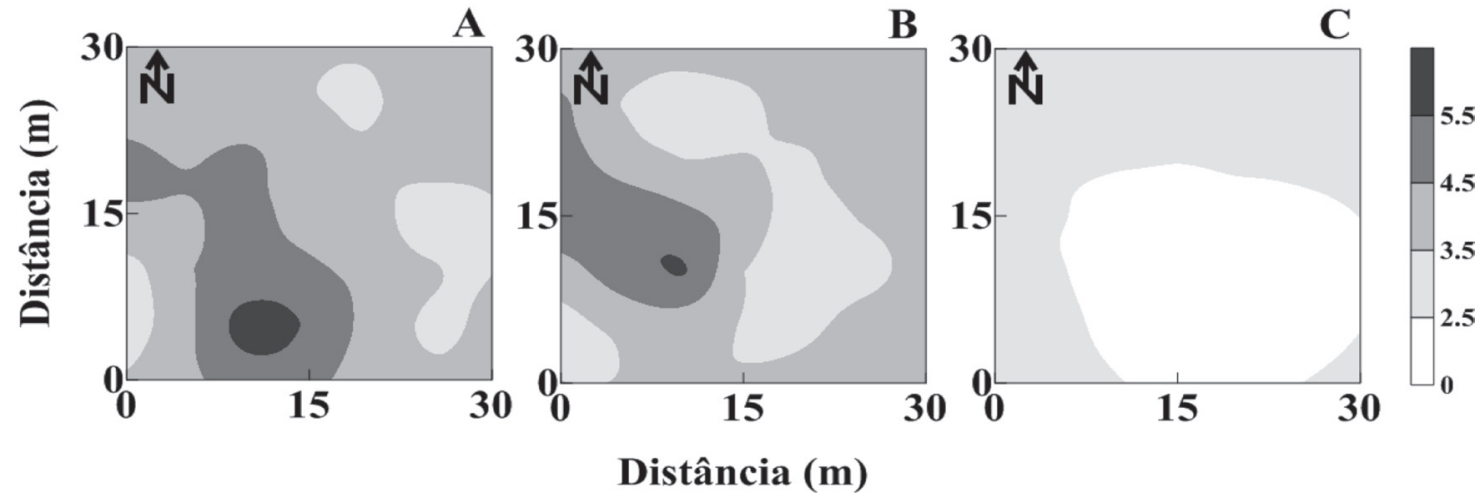

Figura 2 - Mapas de isolinhas da distribuição espacial do estoque de carbono (Mg ha-1) na biomassa da gramínea em pastagens de capim-Marandu com nível baixo (A), médio (B) e alto (C) de degradação. 

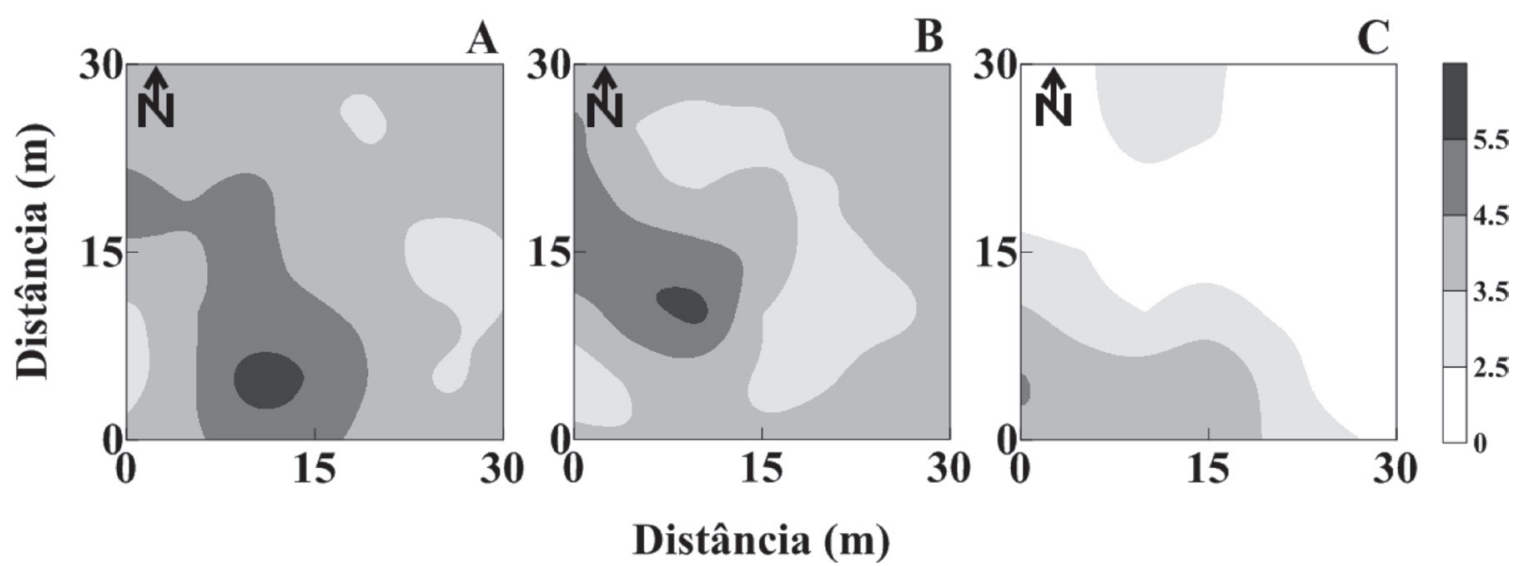

capim-Marandu com nível baixo (A), médio (B) e alto (C) de degradação.
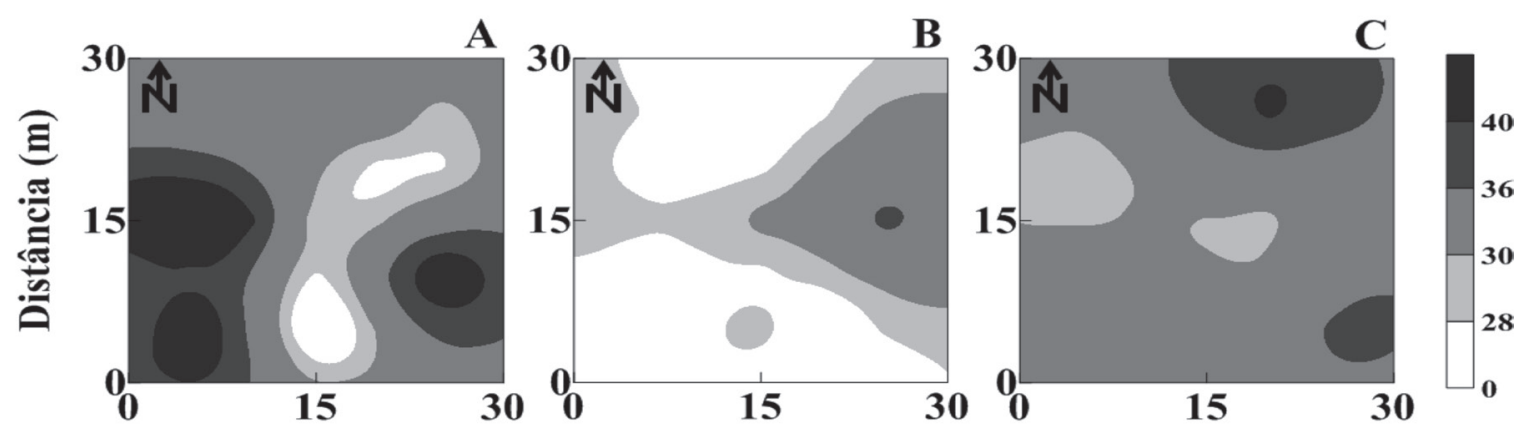

Distância (m)

Figura 5 - Mapas de isolinhas da distribuição espacial do estoque de carbono ( $\left.\mathrm{Mg} \mathrm{ha}^{-1}\right)$ do solo na profundidade de $0-20 \mathrm{~cm}$, em pastagens de capim-Marandu com nível baixo (A), médio (B) e alto (C) de degradação.

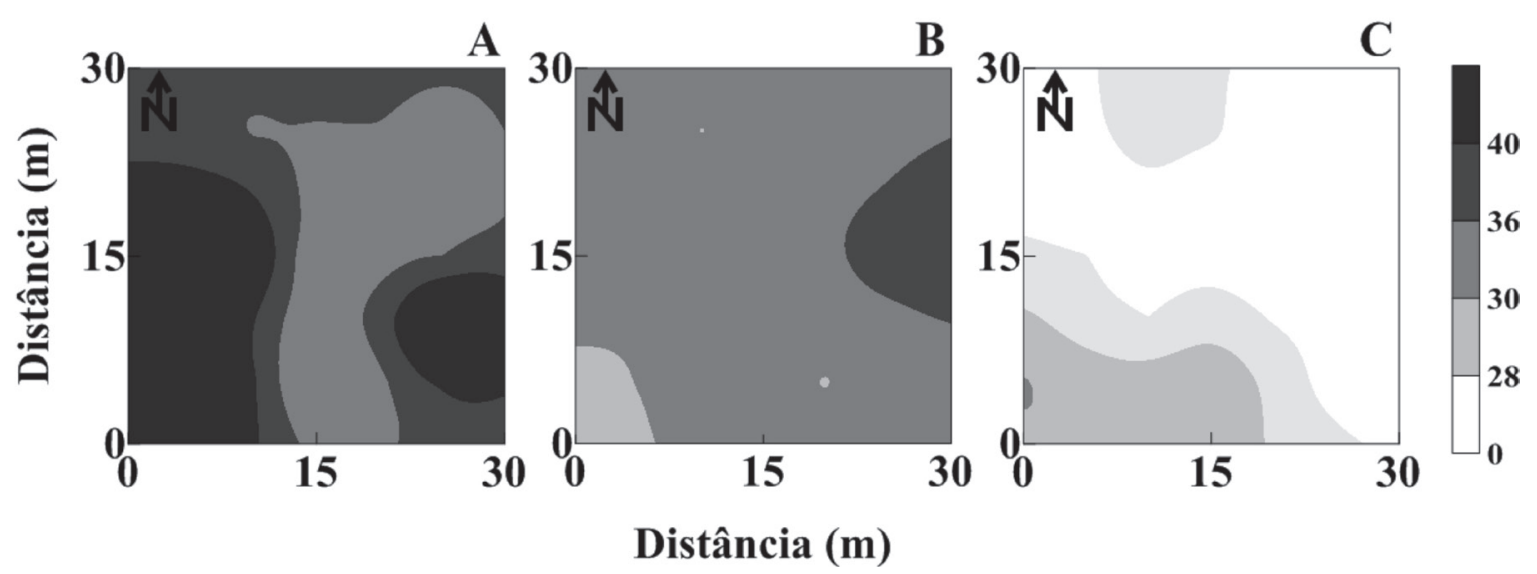

Figura 6 - Mapas de isolinhas da distribuição espacial do estoque de carbono ( $\left.\mathrm{Mg} \mathrm{ha}^{-1}\right)$ no sistema solo x planta (solo + biomassa total) em pastagens de capim-Marandu com nível baixo (A), médio (B) e alto (C) de degradação. 


\section{CONCLUSÕES}

A variabilidade espacial do estoque de carbono é observada dentro e entre as pastagens de capim-Marandu cultivadas em Neossolo Quartzarênico, com nível baixo, médio e alto de degradação.

Pastagens de capim-Marandu com nível baixo de degradação têm menor continuidade espacial por apresentar menores alcances no estoque de carbono na biomassa da gramínea e na biomassa total (Gramínea + Plantas daninhas), no solo e no sistema solo x pastagem (Solo + Biomassa total).

A grade de $5 \times 5 \mathrm{~m}$ é adequada para caracterizar a variabilidade espacial de pastagens de capim-Marandu com grau de degradação baixo e alto.

Área de pastagem de capim-Marandu com grau médio de degradação apresenta coeficientes de variação altos entre os valores de estoque de carbono. O que comprometeu a modelagem espacial que também pode ter ocorrido devido ao baixo número de amostras realizadas $(\mathrm{n}=36)$. Assim, pontos de amostragem menores que $5 \mathrm{~m}$ podem melhorar a precisão dos ajustes dos semivariogramas.

\section{BIBLIOGRAFIA CITADA}

Akaike, H. 1983. Information measures and model selection. International Statistical

Institute, 44: 277-291.

Boddey, R.M.; Macedo, R.; Tarré, R.M.; Ferreira, E.; Oliveira, O.C.; Rezende, C.P.; Cantarutti, R.B.; Pereira, J.M.; Alves, B.J.R.; Urquiaga, S. 2004. Nitrogen cycling in Brachiaria pastures: the key to understanding the process of pasture decline. Agriculture, Ecosystems and Environment, 103: 389-403.

Cambardella, C.A.; Moorman, T.B.; Novak, J.M.; Parkin, T.B.; Karlen, D.L.; Turco, R.F.; Konopka, A.E. 1994. Field-scale variability of soil properties in Central Iowa Soils. Soil Science Society of America Journal, 58: 1501-1511.

Carvalho, P.C.F.; Trindade, J.K.; Mezzalira, J.C.; Poli, C.H.E.C.; Nabinger, C.; Genro, T.C.M.; Gonda, H.L. 2009. Do bocado ao pastoreio de precisão: compreendendo a interface planta animal para explorar a multi-funcionalidade das pastagens. Revista Brasileira de Zootecnia, 38: 109-122.

Castrignanò, A.; Giugliarini, L.; Risaliti, R.; Martinelli, N. 2000. Study of spatial relationships among some soil physicochemical properties of a field in central Italy using multivariate geostatistics. Geoderma, 97: 39-60.

Cerri, C.E.P.; Cerri, C.C.; Paustian, K.; Bernoux, M.; Mellilo, J.M. 2004.Combining soil C and N spatial variability and modeling approaches for measuring and monitoring soil carbon sequestration. Environmental Management, 33: S274-S288.

Chiba, M.K.; Guedes Filho, O.; Vieira, S.R. 2010. Variabilidade espacial e temporal de plantas daninhas em Latossolo Vermelho argiloso sob semeadura direta. Acta Scientiarum. Agronomy, 32: 735-742.
Conant, R.T.; Paustian, K.; Elliott, E.T. 2001. Grassland management and conversion into grassland: effects on soil carbon. Ecological Applications, 11: 343-355.

Dias-Filho, M.B. 2006. Sistemas silvipastoris na recuperação de pastagens degradadas. Embrapa Amazônia Oriental. 31p.

EMBRAPA. 1997. Manual de métodos de análise de solo. 2 ed. Rio de Janeiro. 212p.

EMBRAPA. 2006. Sistema brasileiro de classificação de solos. Brasília: Embrapa produção de informação. 306p.

Faria, A.F.G,; Santos, A.C.; Santos, T.M.; Batistella Filho, F. 2010. Influência do manejo do solo nas propriedades químicas e físicas em topossequência na bacia do rio Araguaia, estado do Tocantins. Revista Brasileira de Ciência do Solo, 34: 517-524.

Feng, Q.; Liu, Y.; Mikami, M. 2004.Geostatistical analysis of soil moisture variability in grassland. Journal of Arid Environments, 58: 357-372

Golden Software. 2002. Surfer for Windows version 8.0. Colorado: Golden.

Gomide, C.A.M.; Gomide, J.A.; Alexandrino, E. 2003. Indices morfogênicos e de crescimento durante o estabelecimento e a rebrotação do capim-Mombaça (Panicum maximum Jacq.). Revista Brasileira de Zootecnia, 32: 795-803.

Gomide, C.A.M.; Gomide, J.A.; Huaman, C.A.M.; Paciulo. D.S.C. 2002. Fotossíntese, reservas orgânicas e rebrota do capimmombaça sob diferentes intensidades de desfolha do perfilho principal. Revista Brasileira de Zootecnia, 31: 2165-2175.

Igram, L.J.; Sthal, P.D.; Schuman, G.E.; Buyer, J.S.; Vance, G.F.; Ganjegunte, G.K.; Welker, J.M.; Derner, J.D. 2008. Grazing impacts on soil carbon and microbial communities in a mixedgrass ecosystem. Soil Science Society of America Journal, 72: 939-948.

IPCC. 2000. Watson, R.T.; Noble, I.R.; Bolin, B.; Ravindranath, N.H.; Verardo, D.J.; Dokken, D.J., (Eds.).Land use, land-use change and forestry. Intergovernmental Panel on Climate Change (IPCC). Cambridge University Press, UK. 375p.

IPCC. 2006. Guidelines for National Greenhouse Gas Inventories, Prepared by the National Greenhouse Gas Inventories Programme - Grasslands. Eggleston H.S.; Buendia L.; Miwa K.; Ngara T.; Tanabe K. (Eds.). Published: IGES, Japan. 6: 1-49.

Kravchenko, A.N. 2003. Effect of spatial structure on mapping accuracy and performance of interpolation methods. Soil Science Society of America Journal, 67: 1564-1571.

Kravchenko, A.N.; Robertson, G.P.; Hao, X.; Bullock, D.G. $2006 a$. Management practice effects on surface total carbon: Differences in spatial variability patterns. Agronomy Journal, 98: 1559-1568.

Kravchenko, A.N.; Robertson, G.P.; Snap, S.S.; Smucker.A.J.M. 2006b. Using information about spatial variability to improve estimates of total soil carbon. Agronomy Journal, 98: 823-829.

Laca, E.A. 2009. Precision livestock production: tools and concepts. Revista Brasileira de Zootecnia, 38: 123-132.

Machado, L.O.; Lana, A.M.Q.; Lana, R.M.Q.; Guimarães, E.C.; Ferreira, C.V. 2007. Variabilidade espacial de atributos químicos 
do solo em áreas sob sistema plantio convencional. Revista Brasileira de Ciência do Solo, 31: 591-599.

Matheron, G. 1963. Principles of geostatistics. Economic Geology, 58: 1246-1266.

Minasny, B.; McBratney, A.B.; Whelan, B.M. 2006. VESPER version 1.62. Australian Centre for Precision Agriculture, McMillan Building A05. The University of Sydney, NSW. (http://www. usyd.edu.au/su/agric/acpa).

Müller, M.M.L.; Guimarães, M.F.; Desjardins, T.; Mitja, D. 2004. The relationship between pasture degradation and soil properties in the Brazilian amazon: a case study. Agriculture, Ecosystems and Environment, 103: 279-288.

Oliveira, O.C.; Oliveira, I.P.; Alves, B.J.R.; Urquiaga, S.; Boddey, R.M. 2004. Chemical and biological indicators of decline/ degradation of Brachiaria pastures in the Brazilian Cerrado. Agriculture, Ecosystems and Environment, 103: 289-300.

Robertson, G.P. 1998. GS+: Geostatistics for the environmental sciences - GS+ User's guide. Plainwell, Gamma Design Software. 152p.

Salton, J.C.; Carvalho, P.C.F. 2007. Heterogeneidade da pastagemcausas e consequências. Embrapa Agropecuária Oeste. 41p.

Silva, S.C. da; Nascimento Júnior, D.; Euclides, V.B.P. 2008. Pastagens: conceitos básicos, produção e manejo. Viçosa: Suprema. $115 \mathrm{p}$.

Schaffrath, V.R.; Tormena, C.A.; Gonçalves, A.C.A.; Oliveira Junior, R.S. 2007. Variabilidade espacial de plantas daninhas em dois sistemas de manejo de solos. Revista Brasileira Engenharia Agricola e Ambiental, 11: 53-60.

Schlesinger, W.H. 2000. Carbon sequestration in soils: some cautions amidst optimism. Agriculture, Ecosystems and Environment, 82: 121-127.
Scholes, M.C.; Powlson, D.; Tian, G. 1997. Input control of organic matter dynamics. Geoderma, 79: 25-47.

Smith, P.; Martino, D.; Cai, Z.; Gwary, D.; Janzen, H.; Kumar, P.; McCarl, B.; Ogle, S.; O’Mara, F.; Rice, C.; Scholes, B.; Sirotenko, O.; Howden, M.; McAllister, T.; Pan, G.; Romanenkov, V.; Schneider, U.; Towprayoon, S.; Wattenbach, M.; Smith, J.2008. Greenhouse gas mitigation in agriculture. Philosophical Transactions of the Royal Society B - Biological Sciences, 363: 789-813.

Spain, J,M.; Gualdrón, R. 1988. Degradación y rehabilitación de pasturas. In: Lascano, C.E.; Spain, J.M. (Eds.). Establelecimiento y renovación de pasturas. CIAT. Cali. 269-283.

Thuille, A., N. Buchmann, and E. D. Schulze. 2000. Carbon stocks and soil respiration rates during deforestation, grassland use and subsequent Norway spruce afforestation in the Southern Alps, Italy. Tree Physiology, 20:849-857.

Vieira, S.R. 2000. Geoestatística em estudos de variabilidade espacial do solo. In: Novais, R.F.; Alvarez, V.H.; Schaefer, C.E.G.R. (Eds.) Tópicos em ciência do solo. Viçosa: Sociedade Brasileira de Ciência do Solo, 1: 1-53.

Warrick A.W.; Nielsen, D.R. 1980. Spatial variability of soil physical properties in the field. In: HILLEL, D. (Ed.). Application of soil physics. New York: Academic Press. 319-344.

Webster, R., Oliver, M.A. 1992. Sample adequately to estimate variograms of soil properties. European Journal of Soil Science, 43: 177-192.

Worsham, L.; Markewitz, D.; Nibbelink, N. 2010. Incorporating spatial dependence into estimates of soil carbon contents under different land covers. Soil Science Society of America, 74: 635-646.

Recebido em: 21/02/2011

Aceito em: 27/12/2011 